\title{
Afistaria
}

\section{Vicente Morales Duárez, Maestro, Jurista y Político Liberal}

\author{
Pot Daniel Valcárcel \\ Con la eloqüencia y el buril copiando \\ Tu alma y tu rostro supo diestramente \\ Conservarte la Patria aquella vida \\ - Con quien no mide su poder la muerte \\ (1).

\section{INTRODUCCION}

El criollo limeño Viceñe JoséaMorales Duárez (2) -nacido en la Ciudad de los Reyes êt día 24 decenero ded 1755 y muerto el dos de abril del año 1812 - pertenece a una generación precursora de un nuevo período histórico. Fué coetáneo de otro prócer nuestro: el ariqueño Hipólito Unanue -cuyo segundo centenario celébrase de manera simulánea (3).

(1) v. lámina III y Nota 8.

(2) Hay ciertas diferencias en las noticias genealógicas publicadas por Luis Alayza Paz Soldán y Néstor Puertas Castro (Julio Manuel del Portillo, liberal y castillista en El Comercio Lima, 24-VIII-1954). Examínese más adelante, la Reseña biográfica de este breve ensayo.

(3) La Sociedad Peruana de Historia celebró, el 13 de diciembre de 1955, una sesión académica especial, destinada a conmemorar el segundo centenario del nacimiento de Vicente Morales Duárez e Hipólito Unanue, habiendo pronunciado sendos discursos los Miembros de Número Drs. Carlos Daniel Valcárcel y Juan B. Lastres, respectivamente. Por encargo de la Sociedad y, asimismo, a nombre de la Facultad de Letras de la Universidad Nacional Mayor de San Marcos, el Dr. C. D. Valcárcel publicó el día del nacimiento de Morales Duárez un artículo en El Comercio de Lima. 
Dentro de una genérica actitud progresista ilustrada -que prende y se propaga en el Perú durante el último cuarto del siglo XVIII-, Morales Duárez y Unanue representan a una generación ya en trance de madurez, característica del último lapso del tidelismo absolutista, cuyos primeros representantes en el Perú de la segunda mitad de aquel siglo son el chachapoyano Toribio Rodríquez de Mendoza (1750-1825) y el limeño José Baquíjano y Carrillo (1751-1817). Unos pasarán a la siguiente etapa constitucionalista y quedarán allí, por ejemplo Morales Duá$r \leqslant z$ o Baquíjano y Carrillo, mientras otros llegarán hasta el final de la etapa separatista, como Rodríguez de Mendoza, o vivirán los años iniciales de la República, como Unanue (4).

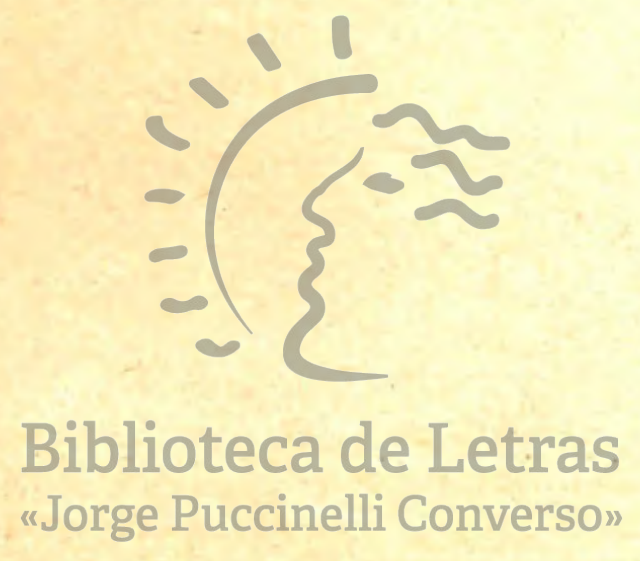

(4) Fidelismo y Separatisno en el Pcrú por D. V., en Revista de Historia de Hasstoria de América Nos. 37-38 (México, 1954). Sobretiro publicado por el Instituto Panamericano de Geografía e Historia de México. 


\section{ESCORZO BIBLIOGRAFICO}

Aunque algo olvidado -si aquilatamos su auténtica importancia histórica-, existe cierta continuidad bibliográfica que acredita interés acerca de la vida y obra del prócer limeño. Aparte de lo poco que dejó escrito -impreso y extraviado o en trance de investigación-, se trata de citar algunos escritos acerca de Morales Duárez. Punto de partida es el año de su fallecimiento. En 1812 publica el canónigo José Manuel Bermúdez su Oración Fúnebre (5) y el Cabildo limeño consagra a su memoria un impreso, titulado Honores Patrios (6). En la etapa republicana del siglo pasado, dedican estudios al prócer limeño: José Antonio de Lavalle (Don Vicente Morales Duárez en La Revista de Lima t. I; reedición póstuma en Estudios Históricos, Lima 1935), Manuel de Mendiburu (Diccionario Histórico-biogrático del Perú). En la presente centuria se han redactado ensayos de varios autores - escritos con ocasión del centenario de las Cortes de Cádiz-; de Luis Alayza Paz Soldán (Revista Histórica, t. XI, Lima 1937, y Revista del Instituto Sanmartiniano, VII1945, y la Constitución de Cádiz de 1812. El egregio limeño Morales y Duárez, Lima, Edt. Lumen, 1946, 98 pp.); de Luis Antonio Eguiguren (Dic cionario Histórico Cronológico; Lima, Imp. Torres Aguirre, t. I, 1940, Y t. III, 1951); y del suscrito (en EI Comercio de Lima, 24-1-1955 y un libro en preparación). En España, la bibliografia pertinente gira en torno a estudios sobre el movimiento uiberaklyi CaoConstitución de 1812 .

$\mathrm{Su}$ iconografía está representada por un retrato de cuerpo entero, con su correspondiente leyenda, existente en el decanato de la Facultad de Derecho de la Universidad Nacional Mayor de San Marcos (7);

(5) Oración Fúnebre / Del Señor / Don Vicente Morales / Duárez; / Presidente / Del Soberano Congreso Nacional. / Que Dixo En La Santa Iglesia Catedral / De Los Reyes: En VII. De Noviembre: / El Señor Canonigo Magistral / D. D. José Manuel Bermudez. / Lima. / Imprenta de los Huerfanos: / Por D. Bernardino Ruiz. / MDCCCXII.

(6) Honores Patrios / Consagrados a La Tierna Memoria / Del Señor / Don Vicente Morales Y / Duarez, / Presidente / Del Augusto Congreso de Córtes, / Por El Excmo. Cabildo / De Esta Capital De Lima. / En VII. De Noviembre De 1812. / Lima: Imprenta De Los Fuerfanos: 1812. / Por Don Bernardino Ruiz. (Con retrato de V. M. D., "Grabado en Lima p. Marcelo Cabe1lo").

v. lámina·IV.

(7) v. lámina I. 
otro retrato se encuentra en la casa de la Sra. Dña. Elena Ferreyros viuda de Bright (8), del cual ha provenido el que se encuentra en la casa del Sr. Dn. Carlos Alayza y Roel, retrato que se halla en el Colegio de Abogados de Lima. También existe una medalla conmemorativa de las Cortes de Cádiz.

\section{RESEÑA BIOGRAFICA.}

1.

El enfoque biográfico de Vicente Morales Duárez descubre la vigencia de dos etapas claramente definidas, aunque dueñas de una marcada desarmonía cronológica. Su existencia corresponde a una vida contenida por la estrechez del medio colonial peruano. La auténtica tendencia liberal del criollo limeño, permanece latente mientras vive en el Perú; se hace patente cuando pasa a la metrópoli, dueña de un circunstancial ambiente renovador.

La primera etapa (1755-1810) corresponde a su momento inicial de formación, de docencia superior, de actividad administrativa, profesional y cultural en el Peru. Puccinelli Converso"

Fueron padres del prócer criollo los peninsulares Doña María Mercedes Duárez y Anzures y el Capitán Don Vicente Antonio Morales y Santisteban -originarios de Granada. Por línea materna descendía del fundador de Chuquisaca y Arequipa Don Pedro de Anzures de Camporredondo, viejo conquistador muerto en la batalla de Chupas. Como el prócer limeño Morales Duárez muriera soltero y sin dejar sucesión, sus actuales familiares vienen de su hermana Doña Rosa, con quien viviera y a quien designara heredera universal de sus bienes, línea familiar que a continuación se inserta.

(8) El retrato existente en la casa de la Sra. Elena vda. de Bright, parece ser el mismo que aparece en el folleto Honores Patrios (Lima 1812). Por declaración del Sr. Carlos Alayza y Roel, sábese que encontrándose muy deteriorado, se trasladó y puso en dicha ocasión la leyenda actual hace, más o menos, un cuarto de siglo. El mencionado retrato aparece reproducido en la lámina III. 


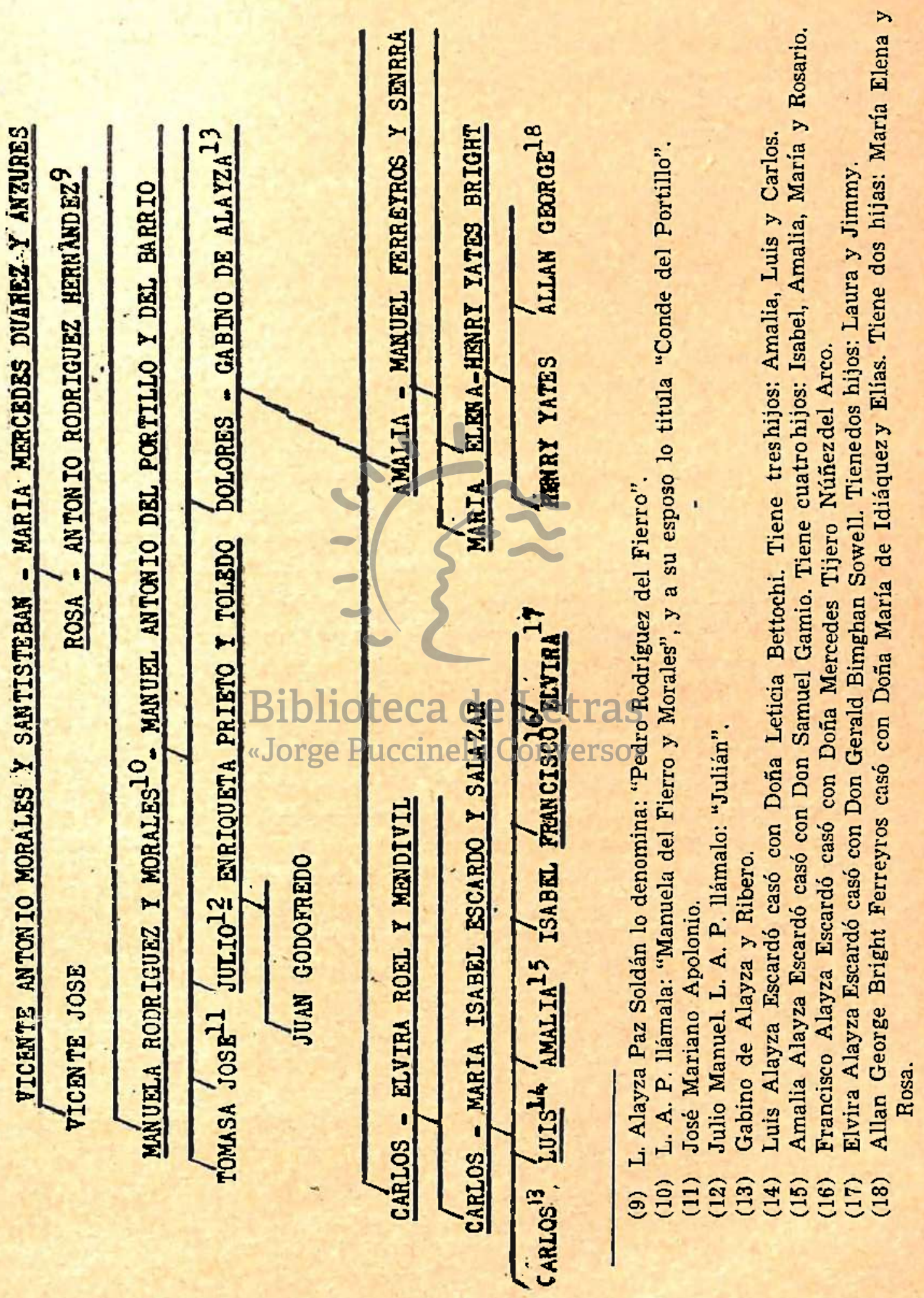


Esta inicial elapa tiene un aspecto pasivo y otro activo. Pertenece el primero a su momento de estudiante; el segundo, a su actividad pedagógica en el Convictorio de San Carlos y en la Real y Pontificia Universidad de San Marcos, en la administración pública, en su profesión de abogado y en la organización institucional a fines del siglo XVIII y comienzos del XIX.

Recibe una inicial educación tradicional y ultramontana en el Seminario de Santo Toribio, bajo el rectorado del eclesiástico panameño Agustín de Gorrichátegui - muerto en Urubamba cuando era Obispo del Cusco (19). Frisaba en los 12 años al producirse en el Perú -y el Imperio Español- la famosísima expulsión de los jesuítas, reflejo enciclopedista de importantes consecuencias históricas para América. Por refundición de los antiguos Colegios Mayores de San Martín y San Felipe, se funda el Convictorio de San Carlos, el siete de julio del año 1770. Su principal maestro sería Toribio Rodríguez de Mendoza, quien desempeñó el rectorado del Colegio desde 1785. En este novísimo y renovador plantel educativo, Morales Duárez recibe la influencia de las nuevas ideas imperantes en Europa. Ya como aprovechado alumno carolino aparece en un acto público académico, presidido por Rodríguez de Mendoña el año 1773 (20). Después de tan brillante prueba -en presencia del virrey Amat-, asciende de estudiante a maestro y comienza su carrera docente en el Convictorio carolino Sus estudios universitarios en la Real y Pontifícia Universidad de San Marcos, culminan con la obtención de los grados académicos de Bachiller,' Licenciado y Doctor en Teología y en ambos Derechos (canónico y civil).

Al recibir los máximos grados académicos de la Universidad limeña, pasa a formar parte del claustro sanmarquino, aunque todavía sin haber sido elegido Catedrático. Aquella costumbre colonial de incorporar al Claustro universitario a los graduados está hoy en desuso, pues éste actualmente se encuentra constituido exclusivamente por los Catedráticos. Desde entonces el ilustre limeño aparece actuando en los principales hechos de la más antigua Universidad americana. Por ejemplo, el año 1781 asiste a la adjudicación de la cátedra de Vísperas de Medicina al Dr. Juan de Aguirre; el año 1783 acompaña al famoso catedrático de Vísperas de Leyes, Dr. José Baquíjano y Carrillo, en su célebre conato reformista, ocasión en que saliera derrotado por la estrechí-

(19) v.Rebeliones Indígenas por D. V., II parte, pp. 88.

(20) Medina cita una hoja impresa, referente al acto académico. (cfr. La Imprenta en Lima, t. III, p. 52, No 1363). 
sima diferencia de tres votos al realizarse la recordada elección de tres de agosto del año 1783. Morales Duárez depositó su voto bajo la advocación de San Cosme - como aparece del inédito Libro XIV de Claustros (21), cuyo texto es importante para seguir la actividad universitaria de Jan Marcos a fines del siglo XVIII. Al año siguiente votó, bajo el sig no de Santa Rosa, en la elección del nuevo Rector, Dr. Francisco de Tagle y Bracho, y formó parte de una Comisión que debía examinar las Constituciones de la Universidad y presentar un proyecto de reformas. En 1798 aparece firmando, con el Claustro, para que la Universidad envíe un donativo a España.

Inicialmente enseñó en la Facultad de Teología, la asignatura de El Maestro de las Sentencias, parece que como Catedrático Adjunto (22). Su carrera de Catedrático estable, iníciase en 1792. Por oposición, cabe decir en reglamentaria competencia universitaria, obtiene la cátedra de Instituta en la Facultad de Leyes, el día 15 de julio, con cuya ocasión circularon unas Décimas (23), repartidas por los religiosos de la Orden de San Camilo - de cuya congregación era Abogado. Derrotó en tan magna ocasión a prestigiosos académicos como los Drs. Manuel Antonio Noriega, Casimiro Sotomayor y José Alexandro Jayo. También por oposición, ocupa la cátedra de Código, el 17 de octubre de 1794, siendo Rector el Dr. Cristóbal Montaño. Se sabe que el año 1793 vivía Morales Duárez en la calle de la Encarnación número 1938 (24).

Desde entonces la carrera universitaria del ilustre limeño incrementa su rango. El ocho de eñero deci793 firmalun Informe -al lado de Baquíjano y Carrillo y otros Catedráticos-, elogiando las prendas intelectuales del bachiller Jacinto Calero y Moreyra, Abogado de la Audiencia, impresor del Mercurio Peruano. Al año siguiente asiste a la jubilación académica del catedrático de Prima de Leyes Baquíjano y Carri1lo. Ya con el prestigio adquirido en la docencia, el Claustro de la Uni-

(21) Este Libro de Claustros es el único que existe de su género. Hubo desde 1563 hasta 182116 Libros de Claustros en el Archivo de la Universidad, hasta la segunda mitad del siglo XIX. EI Libro XIV corresponde al lapso de 1780 a 1790 . (El suscrito prepara una edición de este importantísimo documento universitario).

(22) Así se infiere de la leyenda iconográfica puesta en el retrato de la Facultad de Derecho de la Universidad de San Marcos, cuyo texto ha sido copiado y puesto en otros retratos, restaurados o copiados (v. Escorzo bibliográfico).

(23) Queda un breve impreso de éstas, publicadas aquel mismo año.

(24) v. la Guía del año 1793. 
versidad lo nomina - sin Oposiciones-Catedrático de Vísperas de Cánones el cinco de abril de 1797. Su indesmayable actividad académica se patentiza en exposiciones públicas y discusiones, especialmente el año 1800 con ocasión de disertar José Ignacio Lozano. Asimismo desempeña el cargo de Bibliotecario. Nuevamente el Claustro universitario designa para ocupar la cátedra de Decreto a Morales Duárez, dándole posesión el 27 de agosto del año 1802. Particularmente lo distingue la Universidad, al encargarle sendos Elogios a los prelados Don Manuel Joaquín González Acuña Sanz y Merino, Obispo de Panamá (25), en acio académico de la Universidad de San Marcos realizado el 31 de agosto de 1803, y Don Juan Domingo González de la Reguera, Arzobispo de Lima (26). Al comenzar el siglo XIX, su posición universitaria era óptima. Desempeñó por espacio de cinco años el importante cargo de Conciliario Mayor de la Universidad, elevado sitial académico al lado del Rector de San Marcos (27). Y por enfermedad del Rector Dr. José Silva y Olave ocupó, en julio de 1808, el cargo intelectual más importante del virreinato peruano: el de Rector de la Real y Pontificia Universidad de San Marcos.

(25) Elogio / Del / Ilustrísimo Señor Doctor / Don Manuel Joaquin Gonzalez Acuña Sanz / y Merino, Dignísimo Obispo de / Panamá. / Pronunciado / En la Dedica del Acto Ge-/neral de Filosofía, que consagró a dicho / Señor el Colegial del Real Convictorio / de San Cárlos Don Marcelino Cavero y / Tagle, en la Real Universidad de Sản D Marcos de Lima, el día 31 del próximo / Agosto, / Por / El Doctor Don Vicente Mo- / rales, Catedrático de Decreto en dicha / Real Universidad, y Doctor en Teologia / y ambos Derechos. / Impreso en Lima, en la Imprenta de la Real / Casa de Niños Expósitos. Año de $1803.14 \mathrm{pp}$. v. Lámina II.

(26) Elogio académico / del / Excelentísimo é Ilustrísimo Señor / Doctor Don Juan Domingo Gonzalez de la Reguera, / del Consejo de S. Mag., Caballero Gran-Cruz de / la Real y Distinguida Orden Española de Cárlos / III, Dignísimo Arzobispo de la Santa Iglesia / de Lima: / Pronunciado / en el acto literario que para ob- / tener el grado de Doctor en Teología, le dedicó / Don Tomás Joseph de la Casa y Piedra, Colegial / Maestro del Real Seminario de Santo Toribio, / en la Real Universidad de San Marcos, / el dia 21 de Junio de 1805. / Por / Don Vicente Moráles, Abogado de / esta Real / Audiencia, Doctor en Teología y en / ambos Derechos, y Catedrático de Decreto en / la misma Universidad / Lima M.DCCCV. / En la imprenta de la Real Casa de Huérfanos.

(27) Al lado del Rector existían cuatro Conciliarios: dos Mayores y dos Menores. Uno de los Conciliarios Mayores era el Rector cesante -que también desempeñaba el cargo de Vicerector-, mientras el otro Conciliario Mayor se elegía entre los más prestigiosos Catedráticos. (Cfr. las Constituciones de 1581 - Tit. III, consts. XXXVII - XL-y de 1735 - Tit. III, consts. I - IV. 


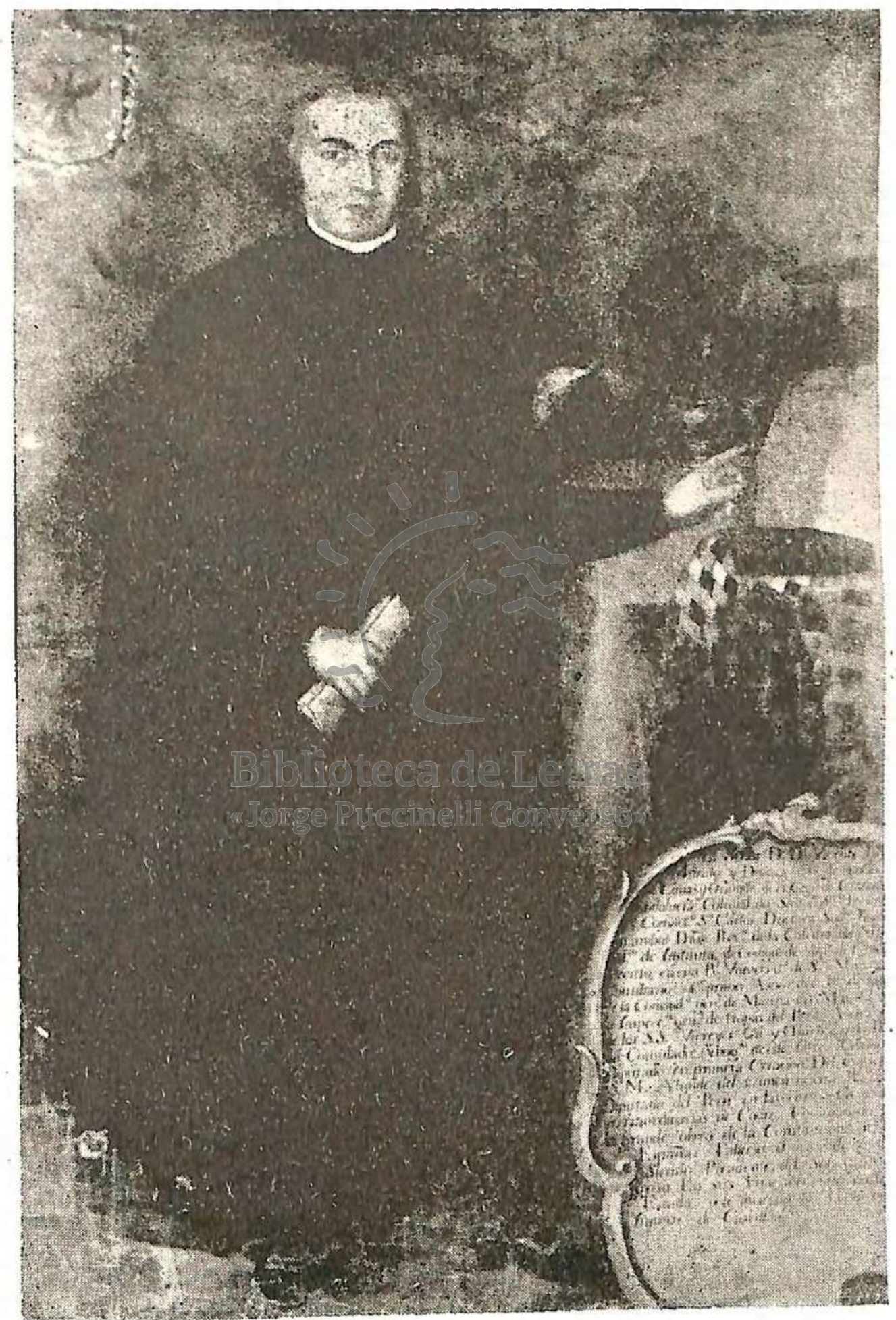

LÁMINA I 


\section{TOG \\ DEL}

ILUSTRISTMO SEÑOR DOCTOR don manuel joaquin gonzalez acuña sanz $Y$ MERINO ; DIGMISIMO OBISPO DE PaNamá.

\section{PRONUNCIADO}

\section{EN IA DEDICA DEL ACTO GE*} neral de Filosofía, que consagró á dicho Señor el Colegial del Real Convictorio de San Cárlos Don Marcelino Cavero y Tagle, en 12 Real Universidad de Sam Márcus de Bilinateradia 3 tisel próximo Agosto,

\section{POR}

EL DOCTOR DON VICENTE MOrales, Catedratico de Decrexo en dicha Real Universidad, y Doctor en Teolocía Y ambos Derechos.

Impreso en Lima, en la Imprenta de la Resl Casa de Niñsos Expósitos. Año de 1803. 
Al emprender viaje a España, a principios de enero del año 1810 , el claustro sanmarquino lo había nominado Procurador de la Universidad. El Cabildo de Lima también parece haberle dado algunos encargos que cumplir en la metrópoli. Lo sustituyó accidentalmente en su Cátedra el Dr. José de Ostolaza — Secretario del Colegio de Abogados-, aunque Morales Duárez dejó establecido que si fallecía en España sería sustituído en propiedad por el Dr. Jacinto Muñoz Calero -Asesor de Rentas de la Real Hacienda. Quedó de apoderado suyo en Lima, su abuelo Don Antonio Rodríguez Hernández, persona que aparece cobrando 372 pesos correspondientes a un semestre de su cátedra de Decreto en la Facultad de Leyes (28). Entre sus discípulos notables podría recordarse, por ejemplo a Vidaurre (29).

Paralelamente a su actividad docente, desarrolló una intensa actividad profesional, habiendo obtenido su grado de Abogado ante la Real Audiencia de Lima, cargo prolesional donde también adquirió justa fama. Actuó al lado de un notable abogado de la época: el Dr. Juan Felipe de Tudela, miembro asimismo del Claustro sanmarquino (30). Al crearse en forma definitiva el Ilustre Colegio de Abogados, por real cédula de 17 de julio del año 1804, Morales Duárez fué elegido Diputado Primero y formó parte del grupo designado para redactar los Estatutos del Colegio. Su nombre aparece en dos invitaciones a nombre del Colegio de Abogados en 1808 y 1809, con ocasión de la "fiesta Votiva del Dulcísimo Corazón de la virgene celebrada entaccapilla de la Universidad de San Marcos (31)e Estaba Yalen España cuando, el 18 de setiembre del año 1810, fue elegido Alcalde del Crimen de la Real Audiencia de Lima.

A sus actividades docentes y profesionales, añadió el cumplimiento de cargos administrativos como funcionario real durante los gobier-

(28) v. descripción genealógica en Reseña biográfica. 1.

Cfr. Cuentas de la Thesoreria (1810-1813), documento inédito del Archivo Central de la Universidad Nacional Mayor de San Marcos. (v. Catálogo, Introducción y Noticia histórica por Daniel Valcárcel. Lima Imp. Miranda, 1949, pp. $76, \mathrm{~N}^{\circ} 568$ ).

(29) Biografía de Manuel Lorenzo de Vidaurre por Pedro Vidaurre. En La Bolsa de Lima, abril-mayo 1841. (Reproducido en Boletín Bolivariano No 6, Lima, Febrero 1929, pp. 160-179).

(30) En un documento inédito del Archivo Central de la Universidad de San Marcos, aparece el Dr. Tudela recibiendo "propinas". Cfr. Cuentas de la Rl. Universidad (1783-1784). (v. Catálogo, pp. 76, № 567).

(31) v. La Imprenta en Lima de Medina, t. III, pp. 386-87, No 2128, y pp. 403-04, No 2181. 
nos de los virreyes Jáuregui, Croix, Gil də Taboada y O'Higgins. Desempeñó los empleos de Primer Asesor de la Renta de Tabacos, colaboró especialmente en diversos actos del virrey Gil de Taboada y en ocasiones diversas, desempeñó funciones de Asesor de la Subinspección general de Marina del Mar del Sur, empleos que dicen elocuentemente del aprecio que gozaba y de su conocimiento y buen sentido para los negocios públicos.

Como representante cultural de la progresista generación peruana de la segunda mitad del siglo XVIII, formó parte de la Sociedad Académica de Amantes del País, cuya actitud crítico-constructiva se hace ostensible mediante aquel histórico órgano que fué el Mercurio Peruano "de historia, literatura, y noticias públicas", editado por Calero y Moreira, cuyo primer número corresponde al día dos de enero del año 1791. Al lado del Protector (el virrey Francisco Gil de Taboada) y Viceprotector y Juez (el Alcalde del Crimen Juan del Pino Manrique), había un Presidente de la Sociedad (José Baquíjano y Carrillo), un Vicepresidente (José Rossi y Rubí), dos Censores (el P. Tomás Méndez y Gabriel Moreno), un Secretario (Hipólito Unanue), un Tesorero (Tnte. de Policía José María Egaña), un Diputado (Jacinto Calero), Socios, Foráneos, Consultores y Miembros Honorarios. Morales Duárez pertenecía al grupo de Socios.

\section{Biblioteca, de Letras

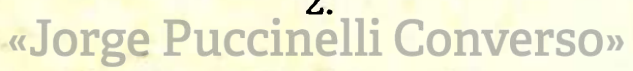

La segunda etapa (1810-1812) es brevísima pero avasalladora y fecunda. Aquí se hace patente el político, cuya dimensión metropolitana e hispanoamericana no ha sido destacada aún con relieves apropiados. Como otros célebres peruanos - Garcilaso u Olavide-, viajó a España para no volver jamás al Perú, aunque de no haber fallecido, súbita y prematuramente, tenía el propósito de retornar.

$\mathrm{Su}$ actividad profesional, académica y administrativa, permite a Morales Duárez acumular experiencias y labra la individualidad del eminente limeño. La ocasión de hacer patente esta rica y sugestiva personalidad, aparece al viajar a la península. El 13 de enero de 1810 salía del Callao, a bordo de la Fuente Hermosa. Llega a las Canarias cuatro meses después. El Capitán General de las islas lo insta a quedarse, "pidiéndolo para oidor y visitador de aquella audiencia", pero el prócer limeño se excusa y sigue su ruta, tras una estada de poco más de un mes. Llega a la metrópoli el siete de agosto de 1810, cuando dramáticamente luchaba el pueblo español contra la invasión napoleónica. 
Como el monarca Fernando VII estaba prisionero, fueron convocadas las Cortes el ocho de setiembre de 1810 en el Convento franciscano de Cádiz. La premura del instante hizo que se eligiesen Diputados suplentes entre los peruanos que residían en Cádiz. Hubo dos elecciones sucesivas, y en ambas Morales Duárez obtuvo el segundo lugar por el número de votos. Representaron a Lima Morales Duárez y Manuel Olaguer Feliú, natural de Chile. La elección se realizó el 20 de setiembre del año 1810. Las Cortes se instalaron cuatro días más tarde.

La estada en España del insigne limeño puede, parcialmente, seguirse mediante sus Cartas, suscritas entre setiembre de 1810 y octubre del siguiente año (32). Le cupo la distinción y responsabilidad de formar parte de las Comisiones de Constitución, Poderes de los Diputados, Justicia para abreviar causas criminales, Arreglo de Provinclas y Supresión de Empleos, todas de grave responsabilidad y desempeño enérgico. Pero su principal labor - la que le hiciera famoso- fué desarrollada en la Comisión de Constitución, que redactara la famosísima del año 1812, jurada el 19 de marzo y en Lima el dos de octubre. Su texto es básico para comprender el desarrollo del liberalismo español posterior y es fecunda simiente de futuras actitudes políticas hispanoamericanas.

Se distingue en este lapso brevísimo un rápido ascenso jerárquico en la carrera parlamentaria de Morales Duárez y una paralela y fecunda actividad política, vinculada al paso de un monarquismo absolutista a otro monarquismo de tipo constituciónalista donde destaca la defensa de los derechos político-sociales del hombre hispanoamericano $-y$ de los otros territorios del Imperio español- que tiende a transformarse de súbito en ciudadano.

El 20 de setiembre de 1810 fué elegido Diputado Suplente por Lima. Su brillante actuación parlamentaria hace que Morales Duárez sea nombrado Vicepresidente de las Cortes, en 24 de noviembre del mismo año. $Y$ en forma accidental preside la asamblea, el siguiente 12 de diciembre, en una histórica sesión donde se decidió presentar, en breve lapso, un proyecto de Constitución de la monarquía. Y el 24 de marzo de 1812 asciende al más alto cargo que un americano podía aspirar: la presidencia de las Cortes, cargo que desempeñaba cuando lo sorprendió la

(32) V. El egregio lumeño Vicente Morales Duárez por Luis Alayza Paz Soldán, Caps. VII - VIII, en Revista Histórica, tomo XI, entregas I - II, pp. $80-92$.

Carta de V. M. D. de 25-IX-1811, citada y reproducida en parte por J. M. Bermúdez en su Oración Fúnebre, pp. 30-31; otra al Cabildo de Lima, parcialmente reproducida por Bermúdez, ibid pp. 33. 
muerte, el dos de abril. Su actividad parlamentaria puede ser conocida por el examen de El Diario de las Discusiones y Actas de las Cortes y se incrementaría con las hasta el presente desgraciadamente extraviadas Memorias de las Cortes de Cádiz, documento que entregara al Marqués de Montemira para ser depositado en manos de su amigo Don Francisco Moreyra Matute para su publicación en Lima. Estando Fernando VII prisionero de Napoleón, el Presidente de las Cortes representaba, legalmente, al monarca. Podría hablarse del limeño que falleció ocupando el sitio del rey, honor máximo hecho a los méritos de un americano. Probado está que deseaba ser enterrado en el novísimo Panteón de Lima (33).

(33) v. Carta de V. M. D. a F. M. y M. 22-I-1811.

v. Gaceta del Gobierno de Lima

En publicaciones contemporáneas existen detalles de su muerte y los honores póstumos que recibió. El primero de abril de 1812, con motivo de su nombramiento de Presidente de las Cortes, Morales Duárez, ya indispuesto, asistió a un banquete dado en su honor por el Marqués de Walesley -embajador inglés. Después, pasó todavía a concluir un trabajo pendiente antes de retirarse a descansar. Su oponente político y compatriota, Blas de Ostolaza, manifestó haber oído ruidos desacostumbrados en la madrugada. Forzada la puerta, eran tardíos ya los auxilios. Falleció pasadas las cinco de la madrugada.

El entierro corrió por cuenta del Estado. El siete de abril de 1812 recibía los honores de Infante de Castilla en las exequias de la iglesia del Carmen, asistiendo dignatarios civiles, eclesiásticos y representantes de naciones extranjeras. Análogos honores fínchres arecibia en la Catedral de Lima. Hubo misa, que cantó el canónigo Manuel Arias, oración fúnebre, pronunciada por el canónigo Bermúdez -impresa aquel mismo año-y a parato solemne, bajo el cuidado del Lic.-Marcos Andrade, ecónomo de la Catedral, por espacio de ocho días. Colaboraron a la pompa de las solemnes exequias el Seminario de Santo Toribio y el Convictorio de San Carlos, lugares de los que fué alumno y maestro, los que le dedicaron poesías alusivas. Entre las personalidades asistentes estuvieron el Virrey Abascal, el Dr. Baquíjano y Carrillo, el Márqués de Montemira, el obispo de Huamanga José Silva, los Prelados de las diversas Ordenes religiosas y miembros de la nobleza. El Cabildo tuvo especial participación.

Una de las Octavas, puestas al pie de su retrato por el Convictorio de San Carlos, inserto en los Honores Patrios, publicados por el Cabildo de Lima (v. Lámina IV) dice:

Morales: á la mas excelsa cima

Del mérito, virtud y honor subiste.

Vivir mas no te diera mas estima,

$Y$ no teniendo ya qué ser, moriste.

Se aflige en ti; pero se goza Lima,

Pues con vida al sepulcro decendiste:

$\mathrm{Tu}$ nombre vive, vive tu memoria,

Dando á ti y á tu patria nueva gloria. 


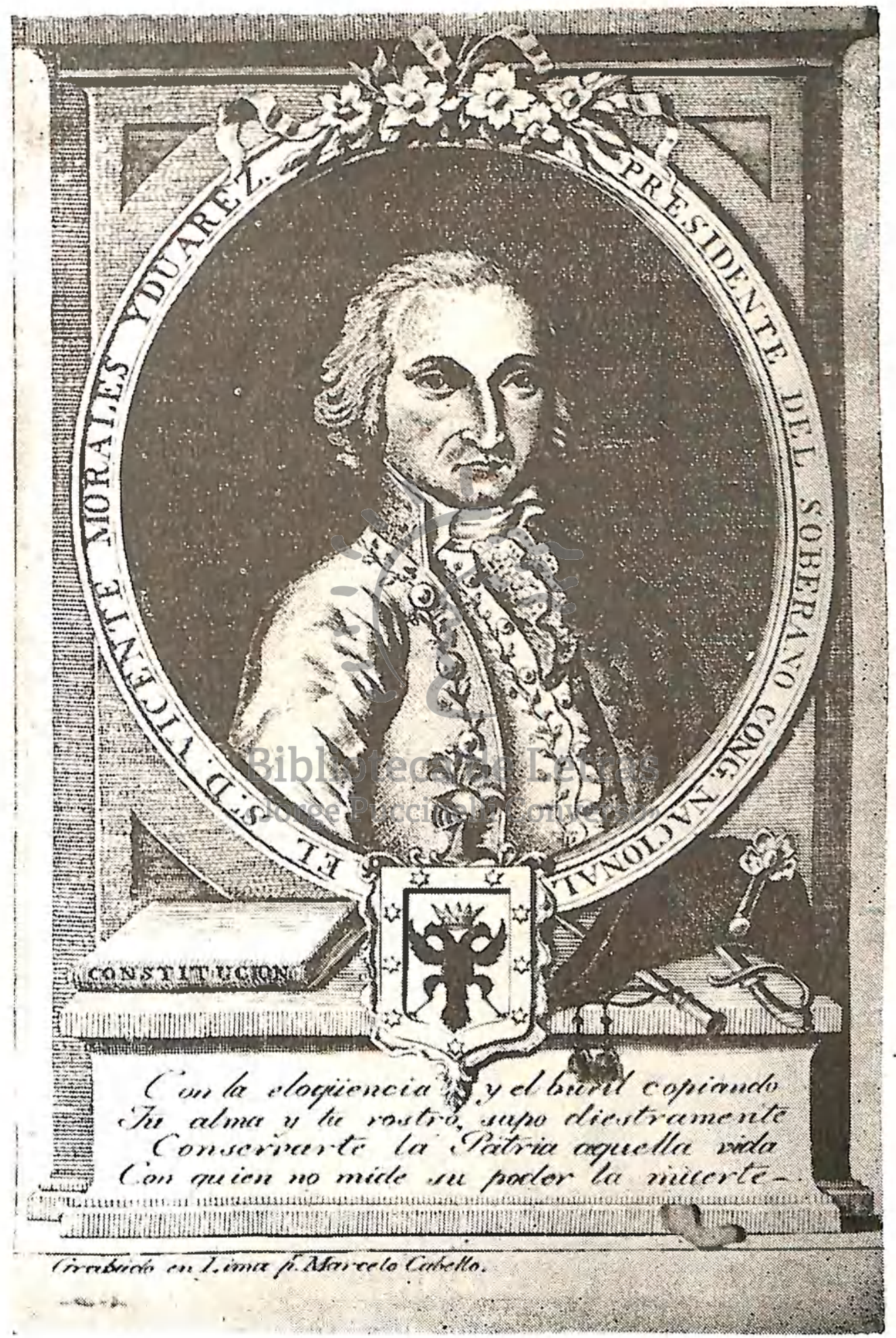

LÁMINA III 


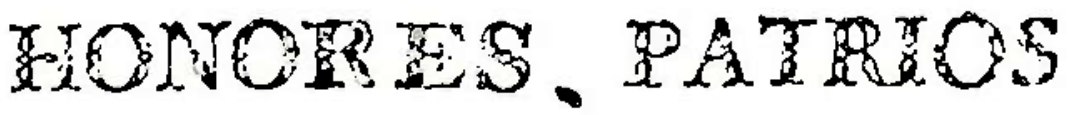

CONSAGRADOS A EA TIERNA MEMORIA

\section{DEL SEÑOR}

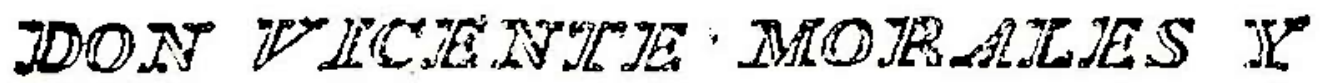
DDUSALAEIZ,

PRESIDENTE

DEL AUGUSTO CONGRESO DE CÓRTES, POR EL EXCHO. CABHLO

DE ESTA CAPITAL DE LIMA,

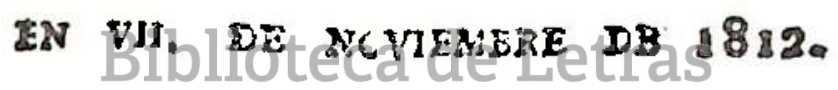
«Jorge Puccinelli Converso»

IIMA: IMPRENTA DE LOS HUERFANOS: $8: \%$. POR DON EERNARDINO RUIZ. 
El famoso liberal criollo aparece como el vocero por excelencia de las aspiraciones políticosociales del hombre colonial y adquiere, de súbito, una insospechada dimensión pública. Algunos importantes momentos de su gestión en España, pueden seguirse en los Libros de Cabildos de la época (34).

Aboga Morales Duárez por un orgánico conjunto de objetivos, cuyo logro traería como consecuencia una mayor y decidida colaboración con la España de aquellos difíciles momentos. Pide con insistencia justicia política para las Colonias, como miembros importantes del Imperio español. Ello se haría patente al promulgarse la célebre Constitución de 1812. Esta justa igualdad de derechos ciudadanos entre los españoles-americanos y los españoles-europeos, será concerniente tanto al número de representantes ante el parlamento español cuanto a la opción de ocupar cargos administrativos. Se tiende a limar - aunque tardíamente- mayores asperezas entre criollos y penirisulares. Con un claro -y siempre actual- sentido de toda auténtica responsabilidad política, sostenía que "La felicidad del país, no consiste en gracias individuales; sino eil planes generales, que a menara de un torrente difundan por todas partes, y por todos tiempos la prosperidad y abundancia" (35). Añadiendo con intuición de prosapia auténticamente política: "para descender al clamor de esta solicitud he tomado dos veces por exordio en mi junta de constitución la protexta seria y expresa de renunciar mis aptitudes á quanto empleo, honor y distintivo me pueda conferir la nacion. El diputado que no piensagen esta forma, (Io será, no de su patria, sino de su persona: desempeñará, no la confianza general, sino las miras particulares de los que acepte y distinga su peculiar interés" (36). Económicamente, argumenta en favor de la libertad de comercio y la extinsión de los odiosos Estancos, con el propósito de rebajar, en parte, el endémico malestar económico y estimular el incremento distributivo de la riqueza privada. Pensaba que la minería, la agricultura y la industria manufacturera textil - con sus odiosísimos Obrajes- debían desarrollarse en vista de la producción y el volumen de las necesidades locales. De esta manera se daba oportunidad a un racional desarrollo industrial y extractivo de las diversas regiones, casi siempre supedita-

(34) v. el Libro de Cabildo No 42, 1810-1812. Ms. inédito del Archivo de la Municipalidad de Lima.

Los Discursos de Morales Duárez y Feliú fueron impresos en la imprenta limeña de los Huérfanos.

(35) J. M. Bermúdez: Ibid, Carta de 25-IX-1811, pp. 31.

(36) Ibid. 
das al macrocéfalo desarrollo de una ciudad básica y superlativamente absorvente. Lima podría ser, para él, un ejemplo aleccionante. Consecuente con la nueva situación política que imperaba, sostuvo la imperiosa necesidad de extinguir los Tributos pagados por el Indio - lo que significaba un repudio a la desigualdad ante la ley- y rehabilitó la personalidad ciudadana del indígena. La simpatía por el elemento autóctono es nota característica del grupo que editó el Mercurio Peruano. Tales reformas traerían como necesaria consecuencia estimular un patriotismo españolizante, que era el patriotismo colonial (37). Junto a tales enunciados, consideró justo asimismo el retorno de los jesuítas expatriados desde la época de Carlos III.

Como acertadamente dijo del limeño Morales Duárez su exégeta, el canónigo historiador Bermúdez: "En su persona se reunian el hombre de bien, el hombre público, el político consumado, el sabio de primer órden, el orador excelente, formado por la naturaleza, perfeccionado por el arte: animado, inflamado por el amor mas ardiente de la patria. Junta sus luces con las de tantos sabios, para disipar las mas densas tinieblas, principio, raiz y funesto origen de nuestras desgracias, y para desconcertar las ideas de la tiranía mas alevosa, mas astuta y fecunda en proyectos destructores" (38). La elocuencia, erudición, buen sentido cotidiano, oportunidad y prudencia desplegadas por Morales Duá$r e z$, son un ejemplo constante para el maestro, el funcionario, el político y parlamentario Detuano. Su acción Cuúblical tuvo siempre objetivos básicos irrenunciabless, pero mostró paralela flexibilidad en su esfuerzo por obtenerlos. Unió a la sapiencia, una madurez de difícil simultaneidad, logrando ver coronados sus esfuerzos legalistas, como pocos hombres del período colonial pudieron contemplarlo. Hay en su vida y obra, por esto, un inextinguible mensaje para los hombres del Perú actual.

(37) La palabra "patria", "patriotismo" es, a veces, vista con ingenuo anacronismo, otorgándosele una significación histórica diferente a la que se usaba en aquel momento. Lo patrio para el hombre colonial está referido a la monarquía española tanto en su sentido genérico como en el local, que funciona con relación a España. La no-patria, lo foráneo significa aquello que rebasa la jurisdicción española, por ejemplo, lo francés, lo inglés y sus respectivos territorios coloniales.

(38) Alusión constitucionalista contra el régimen absolutista anterior, que poco después retornaría. (v. Bermúdez, ob. cit., pp. 29-30). 